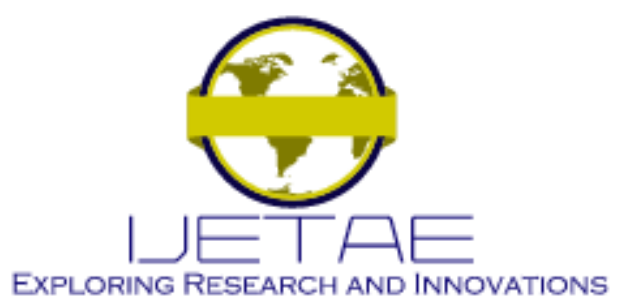

International Journal of Emerging Technology and Advanced Engineering

Website: www.ijetae.com (E-ISSN 2250-2459, Scopus Indexed, ISO 9001:2008 Certified Journal, Volume 11, Issue 09, September 2021)

\title{
Interactive Water Level Control System Simulator Based on OMRON CX-Programmer and CX-Designer
}

\author{
Rijalul Fahmi Mustapa ${ }^{1}$, Rozi Rifin ${ }^{2}$, Mohd Ezwan Mahadan ${ }^{3}$, Aznilinda Zainuddin ${ }^{4}$ \\ ${ }^{1,2,3,4}$ School of Electrical Engineering, College of Engineering, Universiti Teknologi MARA Cawangan Johor, Kampus \\ Pasir Gudang
}

\begin{abstract}
Programmable Logic Controller (PLC) is an essential component in industrial automation where it acts as the backbone of the system. In line with Industrial Revolution (IR) 4.0, most industrial and manufacturing sectors move towards automation systems. Preparing university students about automation and PLC fundamental knowledge and skill is crucial before graduation, where the preoccupied knowledge will enhance graduate employability. Fulfilling this task, universities have to prepare the necessary equipment in the laboratory for teaching and learning purposes. The problem arises when certain universities with budget constraints cannot purchase the equipment for the PLC embedded system as huge costs have to be borne by universities. Thus, an alternative approach has to be taken where the main objective of this paper is to develop an interactive water level control system simulator as a substitution of the expensive automation PLC embedded system for teaching and learning purposes. OMRON software, namely CX-Programmer and CX-Designer used to design and develop an interactive water level control system simulator. In addition, the interactive water level control will be embedded with a PLC component that replicates the actual automation system laboratory equipment. Moreover, universities with a limited budget can utilize the tool for teaching and learning purposes of the PLC and automation system, which is the main contribution of this paper.
\end{abstract}

Keywords - Water Level Control System, Programmable Logic Controller, Simulator, CX-Programmer, CX-Designer.

\section{INTRODUCTION}

Automation is a process that utilizes a specific controller to execute a particular task automatically or requires less human intervention. There are a wide variety of controllers that can be used to implement automation processes. Automation has been classified as an important field in engineering and technology as it is widely used in manufacturing processes [1]. As the importance of automation grew gradually, the automation-related subject has been introduced in Higher Learning Institutions (HLI) to equip students with the desired theory and skills related to the automation system.
Curricular associated with automation subjects were explicitly designed to meet the requirement of governing accreditation bodies. In addition, the automation subject has been made compulsory for most HLI students in the engineering and technology field to be equipped with the necessary fundamental knowledge on automation to increase graduate employability.

The HLI in Malaysia is currently enhancing its Technical, Vocational, Education and Training (TVET) program amongst HLI graduates in line with its transformation in the higher education system. This transformation is one of the objectives of the Malaysian education blueprint [2]. Enhancing the teaching and learning process of the automation subject in HLI can be seen as the best strategy to achieve the desired objective. By the fact that the automation subject combines theory and practice, where both parts are considered crucial to achieving quality TVET graduates. The theoretical parts of automation can be delivered in the lecture hall and classroom, covering the thinking skill domain of the education aspect. Meanwhile, the practical parts typically can be delivered in laboratories; as such, it will cover the psychomotor domain of the technical vocational and training aspects. From the stated domain and aspects, it can be seen that the automation subject carries significant weight as a strategy to ensure that the HLI graduates will have the necessary TVET skill, which eventually ensures the success of Malaysia's transformation in the higher education system.

In recent years, specific research and development from Malaysia's HLI have been conducted in regards to the teaching and learning of the automation subject related to Programmable Logic Controller (PLC) [3] - [5]. PLC is a controller that exists amongst the wide variety of choices in the controller family. PLC is widely used due to its simplicity and user-friendly in governing the automation system [3]. The author in [3] has developed a PLC kit for teaching and learning purposes. 


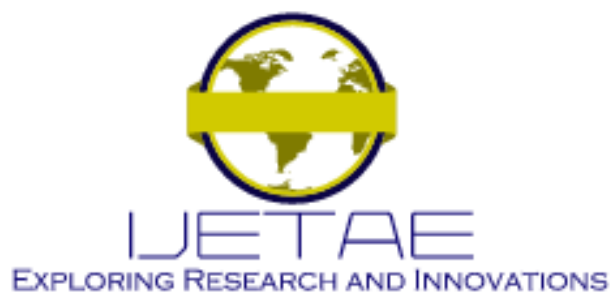

International Journal of Emerging Technology and Advanced Engineering

Website: www.ijetae.com (E-ISSN 2250-2459, Scopus Indexed, ISO 9001:2008 Certified Journal, Volume 11, Issue 09, September 2021)

A PLC kit has been built to overcome the difficulty amongst students pertaining to the connectivity of the input and output between the PLC controller and output modules. The PLC kit holds an advantage where it is compatible with various PLC controllers available in the market. In addition, the same author in [3] developed a multiple inputoutput PLC module for a better understanding of the automation PLC subjects [4]. The developed PLC kit in [4], is a kit that has been developed where the number of output and input was increased to have more connectivity options. The PLC kit has been developed by authors with more sturdy materials and upgraded from the previous developed PLC kit proposed in [3]. Although the use of PLC kit in [3] and [4] has increased students' understanding of PLC subjects, there are certain limitations where PLC kit requires regular maintenance due to unavoidable wear and tear components. In addition, PLC kit requires upgrading from time to time to suit different applications, and new hardware has to be built where prototype manufacturing requires certain costs to be borne. Software pertaining to PLC studies was developed by introducing a tool encapsulating ladder diagram editor, simulator, and compiler in one software [5]. The software has included ladder diagram programming function certain element has been registered in the built-in menu where it will describe the element properties function. The developed software has helps students in the PLC learning process. But some limitation mentioned by the author is available where the software was developed with the PLC system's basic function. In addition, inevitable simulation crashes and lagging processes were observed using the developed software. The mentioned work [3]-[5] was conducted to create a new approach to delivering the theory, concept, and practical work of the automation-based PLC embedded subject in Malaysia's HLI. This approach was proven where the author in [3] [4] provides the statistics of student's improvement based on the approach taken.

In addition, Universiti Teknologi MARA (UiTM) Johor branch Pasir Gudang campus as one of HLI in Malaysia, is not exceptional in teaching automation PLC embedded subjects to its students. Since its operation in 2014, the automation PLC embedded subject is a compulsory subject in its electrical engineering program in the Faculty of Electrical Engineering (FEE). The subject is teaching in classrooms for lecture sessions, while practical sessions were conducted in laboratories.
To provide the best practical session for the students, the faculty must ensure its laboratories were equipped with the best equipment for its practical session. The automation laboratory setup must resemble and replicate the actual equipment used in the industrial environment to avoid the knowledge gap. Providing the best equipment in laboratories for automation subjects will boost student's confidence in handling automation machinery. As the faculty is running on a tight budget, providing the best equipment is impossible as the faculty has to disseminate its annual budget equally to other sections. The limited budget in HLI is not a new issue and is considered a universal problem for HLI since it also has been addressed in [6] and [7]. Even though that is the case, the FEE is committed to providing the best learning experience to equip its student with automation knowledge upon graduation.

This work is motivated and inspired by the Malaysia education transformation to enhance the TVET among HLI students [2] and the researches that were conducted by [3][5] to increase the knowledge grasp in automation subject. The main objective of this paper is to develop an interactive water level control system simulator that resembles the actual equipment used in the industries to enhance the FEE's student knowledge in the automation PLC embedded subject. The simulator was developed using CX-Programmer and CX-Designer software. This paper is divided into five sections. Section II discusses the related literature on the research and development that have been conducted about the teaching and learning of the automation subject. The literature review will discuss the technique used and developed to strengthen the teaching and learning process. Section III will demonstrate the development methodology of the interactive water level control simulator. Meanwhile, Section IV will discuss how the interactive water level controller operates and the discussion towards the results achieved from the simulator. This paper ends with conclusions in Section V.

\section{LITERATURE REVIEW}

The research and development about the teaching and learning process for PLC embedded automation subject specifically in HLI have been conducted as early 2003 [8]. The authors developed a web-based education tool related to the PLC automation subject concentrating on counter instructions lessons. 


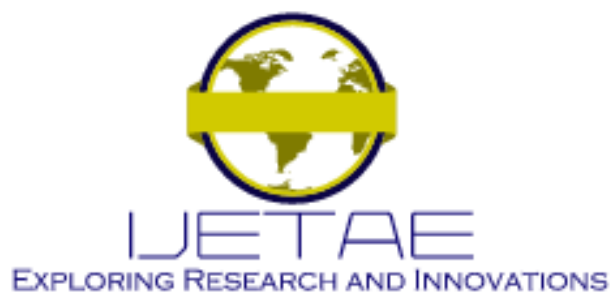

International Journal of Emerging Technology and Advanced Engineering

Website: www.ijetae.com (E-ISSN 2250-2459, Scopus Indexed, ISO 9001:2008 Certified Journal, Volume 11, Issue 09, September 2021)

Animations based teaching and learning were developed to demonstrate the operation of ladder diagram and the operation of counter operates based on switching $\mathrm{ON}$ and OFF. A 3D simulator [9] has been built that resembles an industrial system that utilizes PLC in the automation system. Through the 3D simulator, students can build industrial systems interactively with standard automation components with minimal access to the laboratory as the simulator is remotely controlled by students. The educational platform development for students is present in [10], where the authors have made a platform consisting of an analogue input module, sensors, and a human-machine interface. The features of the educational platform developed by [11] emphasize the involvement of logic gates in designing PLC for automation systems. The platform was built with the idea to offer students in capturing the essence of design, testing and simulating automation systems.

The authors in [12] from the University of Iasi recently has developed a model that replicates a real elevator simulator for its undergraduate students. The elevator model was developed using induction motor, inverter Human Machine Interface (HMI) and PLC module were embedded in the model where students can apply theory and practicality of designing the automation involved in the elevator system. A sorting machine was developed interactively by authors in [13]. It combines web applications as an Interactive Learning Platform for students to set up the sorting machine experiment through a web application. The developed sorting machine ILP has been used amongst 15 students in laboratory sessions, and a survey was conducted. As a result, most of the students were satisfied with using the developed ILP for laboratory sessions. Authors in [14] developed a sorting machine using a proximity sensor where it can sort different materials with a time duration of less than one minute. PLC was highlighted as an essential component to exert the command that was programmed for the sorting process.

A virtual reality machine and remote laboratories were developed in [15] for teaching and learning on automation. The virtual reality machine (VRM) was developed to help students design the automation process that involves controlling a four-level elevator system. Students are then able to simulate the design system in the VRM. In addition, the remote laboratory is available 24 hours per week for students to test the automation process designed in the VRM. The importance of a guided user interface (GUI) for PLC education is shown in [16].
The authors have suggested that the developed GUI experiments for the PLC teaching and learning process may increase student's interest and learning experience towards the knowledge grasp. THE web-based PLC simulator was built by authors in [17], which contains a digital and analogue input outputs channel similar to an industrial automation system. It can help students in the learning process where, from the experiment results, students are motivated to learn the automation, albeit some parts of the web simulator requires upgrade. The mentioned literature [8] - [17] was conducted in HLI outside Malaysia. Recent research work [18] was conducted in Malaysia's HLI to improve the understanding and learning of the automationrelated subject. A training kit prototype was developed and built to enhance the practical aspect of the automation subject. The kit was developed small in size compared to other available training kits. The assessment of student achievements was conducted, and significant improvement is shown where student's assessment results increase by using the developed prototype for learning activities.

All the available mentioned literature has shown improvement towards learning the automation PLC embedded subject. The mentioned literature generally is concentrating on the development of a PLC training kit [3] [4] [18] and interactive studies [8] [9] [10] [11] [17] through the development of learning software tools. A remote laboratory system was developed that consist of hardware and simulation systems were offered in [12] [13] [14] [15]. Studies involving water level control systems for knowledge grasping hence solving the limited laboratory equipment in automation PLC embedded subject, are limited in the literature. Thus, the work in this paper will focus on developing an interactive water level control system in contributing to the gap offered in the available literature towards solving the problem of limited laboratory equipment and enhancing HLI's students' knowledge about automation PLC embedded subjects. An interactive platform will be built using CX-Designer and CXProgrammer. Students will use it as a learning tool to enhance PLC knowledge concerning water level control system that resembles industrial specification automation system. In addition, students may access the interactive system in offline mode as it was built in the form of desktop application GUI because GUI offered advantages in delivering critical information in the teaching and learning process, as were stated in [16]. 


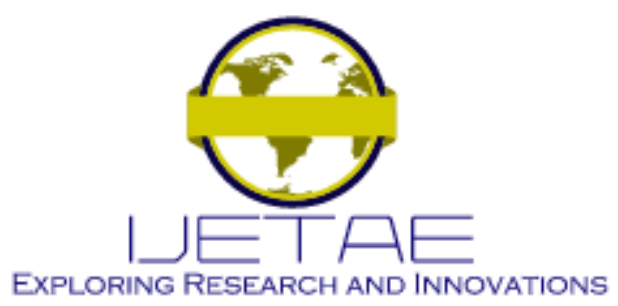

International Journal of Emerging Technology and Advanced Engineering

Website: www.ijetae.com (E-ISSN 2250-2459, Scopus Indexed, ISO 9001:2008 Certified Journal, Volume 11, Issue 09, September 2021)

\section{METHODOLOGY}

In this section, the specific methodology was designed to execute the required experiment to fulfil the objective of this work. It is crucial to have a well-designed method as it will depict the process flow of the proposed technique that will solve the problems stated without deviating from its original objective. As stated in the first section, this work presents the design and development of a water level control system simulator to further enhance the knowledge grasp in automation PLC-related subjects, especially for diploma students in Universiti Teknologi MARA (UiTM) Johor Branch Pasir Gudang campus. This methodology will be divided into three sections to detail out the development of the simulator.

\section{A. Software Package.}

In this work, the first step in developing the simulator lies in choosing a software package. As shown in Table 1, several software packages are available to create the interactive simulator, but it requires licence purchasing for activation purposes. This can be a limitation to HLI due to the expensive cost of license's software purchasing. Table 1 shows the comparison of the software packages in terms of license type, pricing in USD and the features that the PLC equipment manufacturers has offered. From the list of software, OMRON CX-One, which is built-in with $\mathrm{CX}$ Programmer and CX Designer, offered the cheapest PLC software compared to other manufacturers. Furthermore, OMRON PLC software supports the PLC system design and simulation, which features essential to developing the water level control system simulator. Beside, it is costeffective, does not require any equipment to operate, supporting PLC system design and simulation, and is easy to program. CX-Programmer is a PLC programming software commonly used to design, test, and enhance PLC programs associated with Omron PLC. It also provides the foundation for PLC equipment and addresses information support and interfacing with OMRON PLC's hardware. Meanwhile, CX-Designer is one of the OMRON software packages that enable the users to create a Human Machine Interface (HMI) for any OMRON PLC terminal. The CX designer has a variety of functions to permit effective screen formation and troubleshooting [19]. The CXDesigner, enable students to design and test the actual industrial application such as the water level control system, conveyor system, elevator system, and any other industrial automation system in the form of a software interface model called Human Machine Interface (HMI).
The HMI system can create real-time simulation either using PLC ladder logic diagram (LD), Function Block Diagram (FBD), or Sequential Function Chart (SFC), which will be programmed using CX-Programmer.

Table I.

Summary of software packages offered by reputable PLC equipment manufacturers [20]-[23].

\begin{tabular}{|c|c|c|c|c|c|}
\hline No. & $\begin{array}{l}\text { PLC's } \\
\text { Brand }\end{array}$ & $\begin{array}{c}\text { Softwa } \\
\text { res }\end{array}$ & $\begin{array}{c}\text { License } \\
\text { Type }\end{array}$ & $\begin{array}{c}\text { Cost } \\
\text { (USD) }\end{array}$ & Features \\
\hline 1 & $\begin{array}{l}\text { Siemens } \\
\text { PLC }\end{array}$ & $\begin{array}{l}\text { Step } 7 \\
\text { Simatic } \\
\text { Manag } \\
\text { er }\end{array}$ & $\begin{array}{l}\text { Single } \\
\text { Floating }\end{array}$ & 709.09 & $\begin{array}{l}\text { Powerful programming } \\
\text { editor. Optimum } \\
\text { interaction between HMI } \\
\text { and I/O. Support PLC } \\
\text { simulation }\end{array}$ \\
\hline 2 & $\begin{array}{l}\text { Schneide } \\
r\end{array}$ & $\begin{array}{l}\text { SoMac } \\
\text { hine }\end{array}$ & Single & 1065.5 & $\begin{array}{l}\text { Optimize the machine } \\
\text { design, fit the control } \\
\text { configuration, high speed } \\
\text { counting and support PLC } \\
\text { simulation }\end{array}$ \\
\hline 3 & Omron & $\begin{array}{l}\text { CX One } \\
\text { CX } \\
\text { Progra } \\
\text { mmer } \\
\text { CX } \\
\text { Design } \\
\text { er }\end{array}$ & Single & 655.69 & $\begin{array}{l}\text { Support programming } \\
\text { PLCs + HMI, networks, } \\
\text { motion and drive, } \\
\text { regulation and switching } \\
\text { and sensors, easy to } \\
\text { program, support PLC } \\
\text { design and simulation }\end{array}$ \\
\hline 4 & $\begin{array}{l}\text { Mitsubis } \\
\text { hi }\end{array}$ & $\begin{array}{l}\text { MELSO } \\
\text { FT GX } \\
\text { Works3 }\end{array}$ & Single & 1951.6 & $\begin{array}{l}\text { Straightforward graphic } \\
\text { based system } \\
\text { configuration design, PLC } \\
\text { simulation and online } \\
\text { debugging. }\end{array}$ \\
\hline 5 & $\begin{array}{l}\text { Allen } \\
\text { Bradley }\end{array}$ & $\begin{array}{l}\text { RSLogix } \\
500\end{array}$ & Single & 2830 & $\begin{array}{l}\text { Online editing, data table } \\
\text { usage, program compare, } \\
\text { project verifier, drag- } \\
\text { and-drop editing, and } \\
\text { search-and-replace } \\
\text { functions, and support } \\
\text { PLC simulation }\end{array}$ \\
\hline
\end{tabular}

In this paper, the modelling of a water level control system widely used in the industry will be developed using CX-Designer. The components of the system include a water pump, a level sensor for the high position, a level sensor for the low position, an output drain valve, a reservoir, and water pipes. This HMI model later will be used by the students in the laboratory session. Using ladder diagram programming through CX-Programmer, the students were required to automatically program or control the water tank HMI model. With this simulated model, students learning experiences in terms of practical knowledge will be improved since all the students can participate without sharing the lab equipment's which has minimal units available in the lab. 


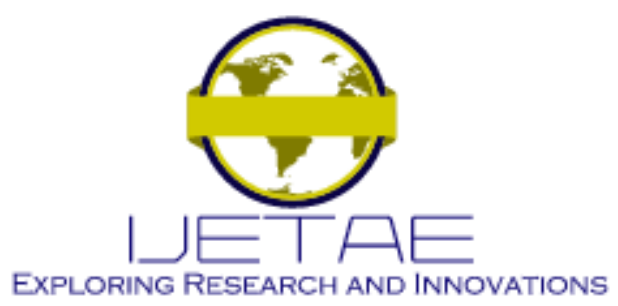

International Journal of Emerging Technology and Advanced Engineering

Website: www.ijetae.com (E-ISSN 2250-2459, Scopus Indexed, ISO 9001:2008 Certified Journal, Volume 11, Issue 09, September 2021)

\section{B. Water Tank Simulator Development}

The water tank simulator in this paper starts with the description of the system's component shown in Figure 1. Figure 1 displays the block diagram illustrating the main components used in a typical water level control system. The ON and OFF button, low water level sensor (LS), and high water level sensor (HS) act as the inputs of the water tank level system. The electrical water pump and drain valve serve as the output components. The electrical water pump is used to supply the water from a water source into a reservoir, while the drain valves will control the water flow conditions if the reservoir is empty. In this simulator, the OMRON $\mathrm{CP} 1 \mathrm{H}$ programmable logic controller is the primary controller to perform the water level control tasks.

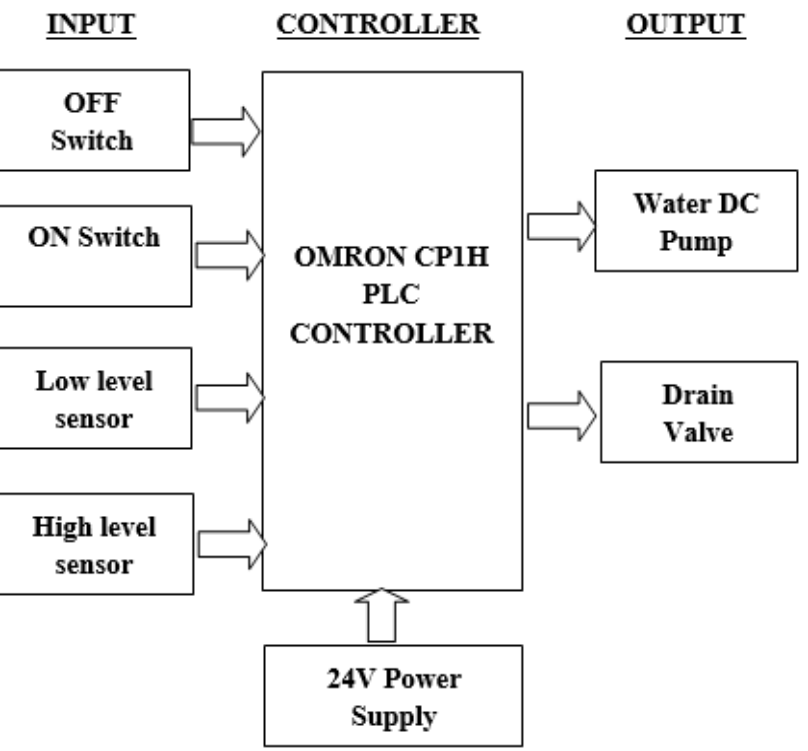

Figure 1. Block diagram for water level control system

The flowchart for water level control system simulator is shown in Figure 2. In Figure 2, the process flow of this work is initiated with the development of a water level control system simulator using a CX-Designer. Subsequently, ladder diagram programming will be constructed through CX-Programmer based on the design requirement in the laboratory's worksheet.

The system integration will be executed if both the system simulator and ladder diagram programming processes are completed without any error. Finally, system integration testing is required to determine the working condition of the system simulator and its program into the interface environment.
If the system simulator fails to produce the expected result, the ladder diagram has to be reprogrammed until it achieved the desired output as per the design requirement.

In order to develop the water level control system simulator that will be available in the remote environment, CX-Designer was applied to design and construct all the components listed in the block diagram shown in Figure 1. Figure $3 \mathrm{a}$ shows the basic water level control system diagram, while Figure $3 \mathrm{~b}$ shows the complete water level system prototype through CX-Designer. It consists of a reservoir, a water pump, water level sensors for low and high positions, ON and OFF pushes-button, a drain valve, and few water pipes. Low and high water level sensors are attached to the reservoir respectively at a minimum and maximum level of water in the tank, as shown in Figure 3.

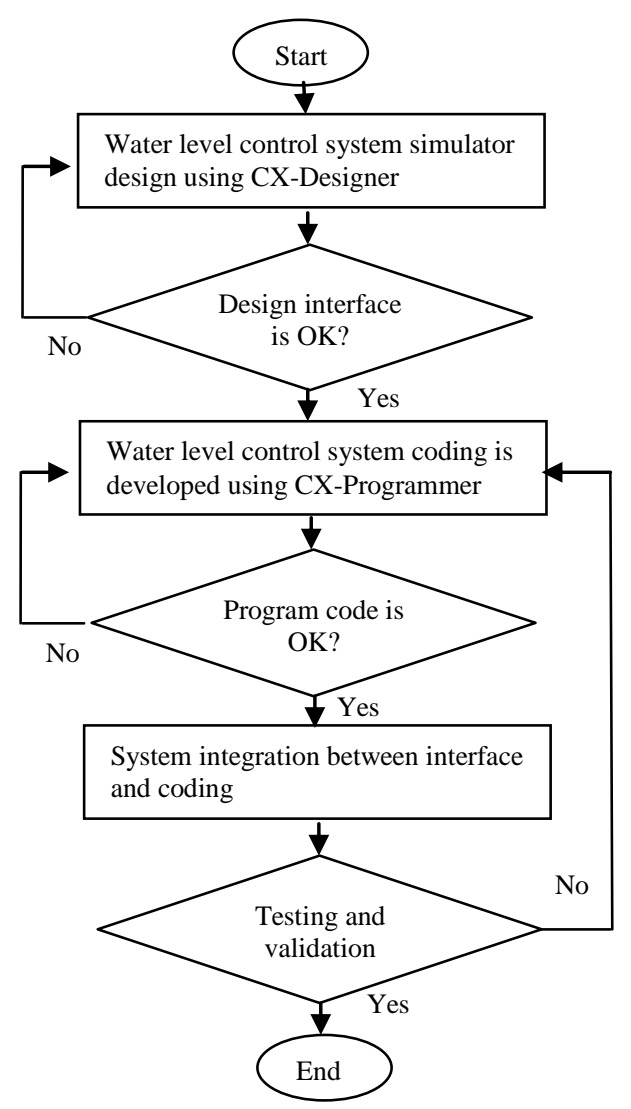

Figure 2. Process flow for the development of the water tank level control system simulator. 


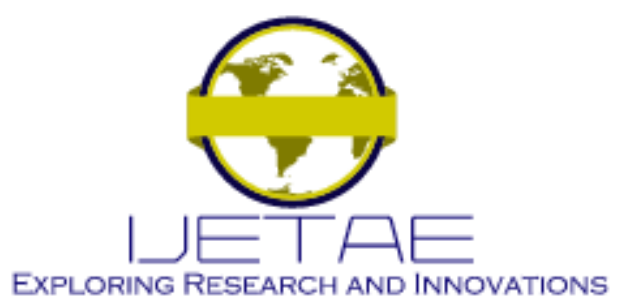

International Journal of Emerging Technology and Advanced Engineering

Website: www.ijetae.com (E-ISSN 2250-2459, Scopus Indexed, ISO 9001:2008 Certified Journal, Volume 11, Issue 09, September 2021)

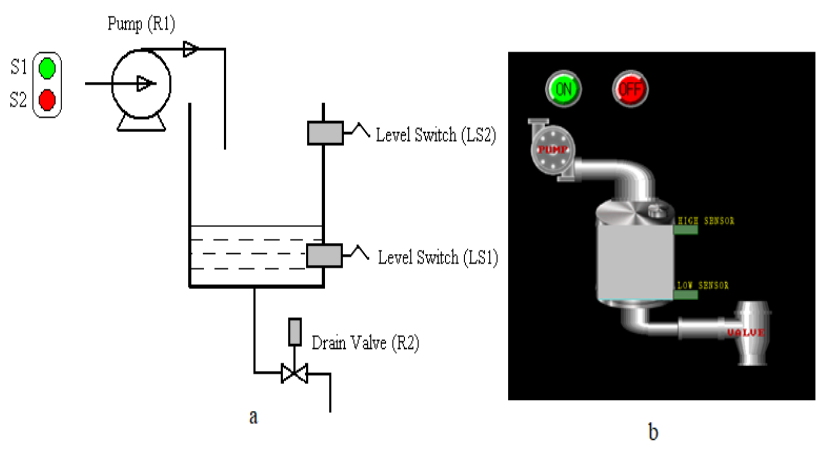

Figure 3. a) Basic diagram of water level control system; b) Water level control system simulator developed using CX-Designer

\section{Ladder Diagram for Water Tank Simulator Control}

The PLC ladder diagram programming in this work is developed using CX-Programmer, where the water level control source code has to be programmed to satisfy the design requirement. Figure 4 depicts the process flow of the design requirement to construct the PLC ladder diagram. According to the design requirement, the water pump will be started once the ON button is pressed. If the water level is reached at a high sensor, the drain valve will be turned $\mathrm{ON}$, and the water pump will be stopped simultaneously. The water will drain out until it is dropped to a low sensor position and cause the water pump to start the pumping process again to refill the water in the reservoir. During the pumping water process, the drain valve is closed. This process will continuously run automatically until the OFF button is pressed to terminate the overall process.

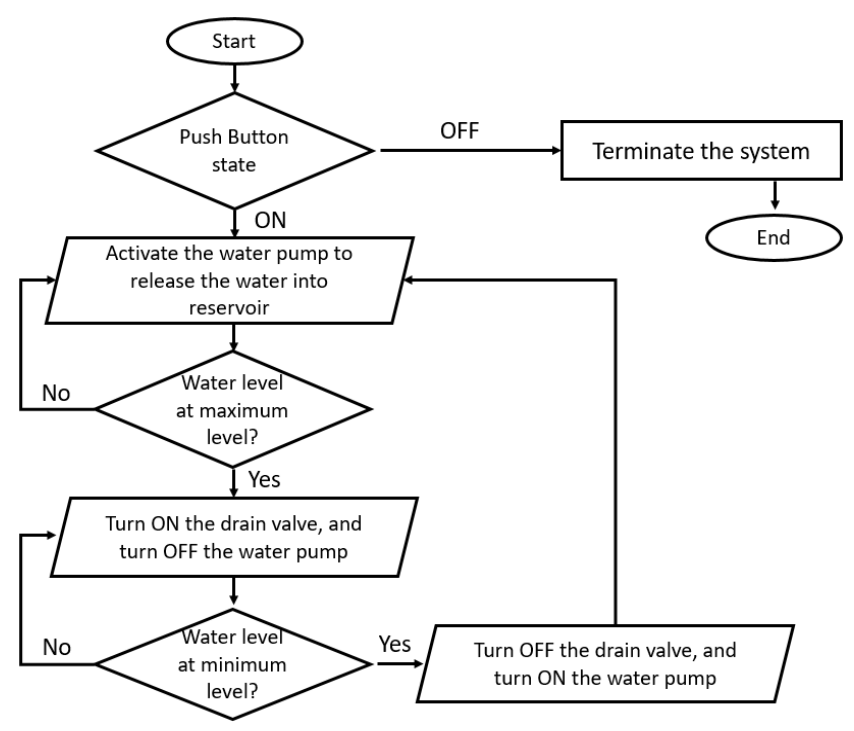

Figure 4. Flowchart of the design criteria

Apart from that, the input-output assignments have to be performed accordingly for the input-output devices of the water level control system. Table 2 shows the example of the input-output assignment, while Figure 5 represents the PLC ladder diagram to control the water level system.

Table 2.

Example of the input-output assignments

\begin{tabular}{|c|c|c|c|}
\hline $\begin{array}{c}\text { Input } \\
\text { Devices }\end{array}$ & Address & $\begin{array}{c}\text { Output } \\
\text { Devices }\end{array}$ & Address \\
\hline ON switch & I: 0.00 & Pump & Q: 100.00 \\
\hline OFF switch & I: 0.01 & Valve & Q: 100.01 \\
\hline Low sensor & W: 0.02 & & \\
\hline High sensor & W: 0.03 & & \\
\hline
\end{tabular}




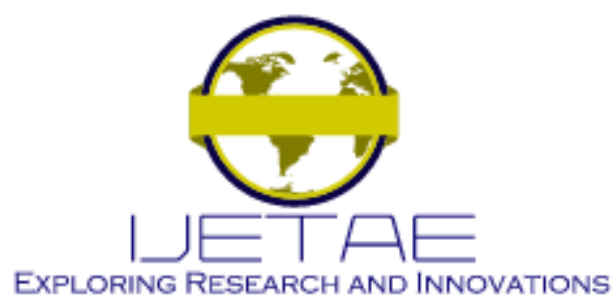

International Journal of Emerging Technology and Advanced Engineering

Website: www.ijetae.com (E-ISSN 2250-2459, Scopus Indexed, ISO 9001:2008 Certified Journal, Volume 11, Issue 09, September 2021)

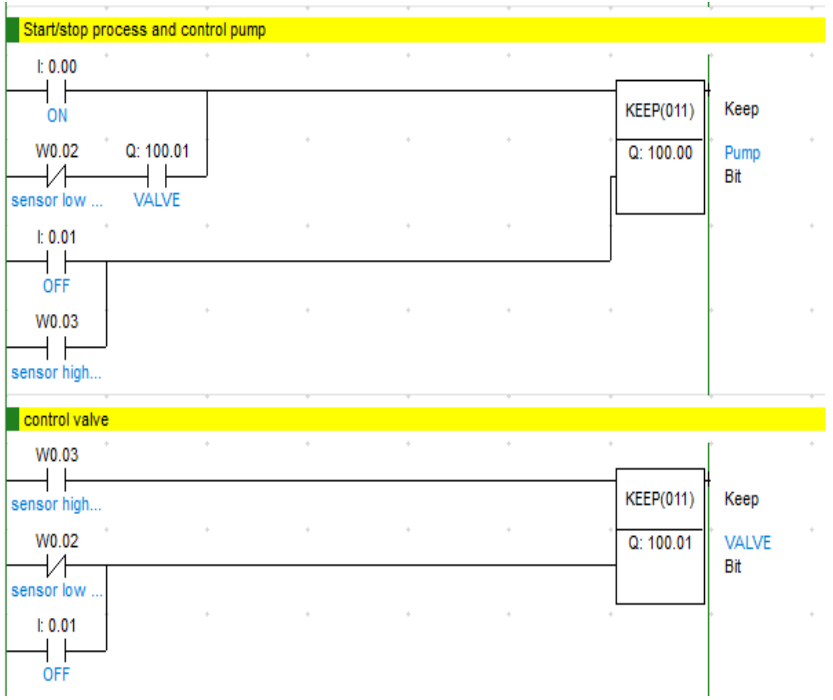

Figure 5. The sample of the PLC ladder diagram for the water level control system simulator

In the final stage, simulator testing has to be executed to ensure the water level system is working as expected. The programming in CX-Programmer has to be conducted within the interface system in CX-Designer. Two important criteria need to be considered for the integration process: firstly, the data type must be in the correct format between programming and simulator. Secondly, the input and output address used in the programming section must be identical to the simulator's address.

\section{RESUlt AND DisCUSSION}

The simulated results of the water level control simulator are shown in Figure 6 and Figure 7 . Two different conditions were depicted for both figures. Figures 6 show that the water tank is at the minimum level, while Figure 7 show the water tank is at the maximum level. In both figures, the main component shown is the pump, tank, ON switch, OFF switch and the valve. The simulation of the water level control starts in Figure 7, where the turn ON switch with the address $\mathrm{I}: 0.00$ was activated. At this particular moment, the water level is at the minimum position. At this position, the LOW sensor (W:0.02) will be activated. Once activated, the pump (Q:100.00) starts to operate and allows water to flow into the water tank.

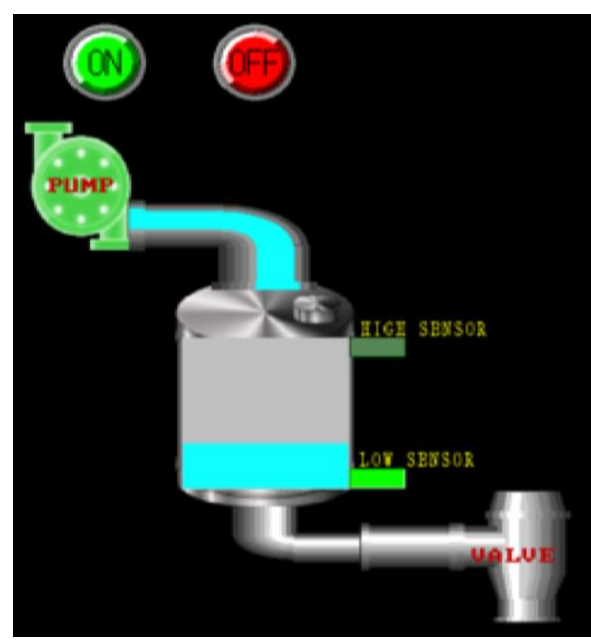

Figure 6. Water at minimum level Condition

The water tank will be filled up with water until it reaches its full capacity, shown in Figure 7. During this condition, the HIGH sensor (W:0.03) will be activated. The $\mathrm{HIGH}$ sensor will ensure that the water from the pump stops filling the water tank. Simultaneously, the valve (Q100.01) will start to operate. The valve will distribute the water in the tank to any outlet that is connected with the valve. The process will be repeated with the previous condition. After the water tank reaches the minimum position, the LOW sensor will be activated, and the water pump starts to operate. The OFF switch (I:0.01) has to be pressed for the termination process to stop the whole process.

The idea in developing the water level control system simulator was derived from the unavailability of the actual hardware to execute the laboratory session of the automation subject. Substituting the real hardware with a developed simulator is an alternative step implemented in the automation subject to ensure the students have been exposed to a water level system before graduating. Before creating the water tank simulator, the most crucial point is that the instructors have to work together to design the important features commonly used in the industries. The next step is that the instructors have to choose suitable software that is easy to develop the simulator. This consideration has to be made because various software packages can develop the water tank simulator. 


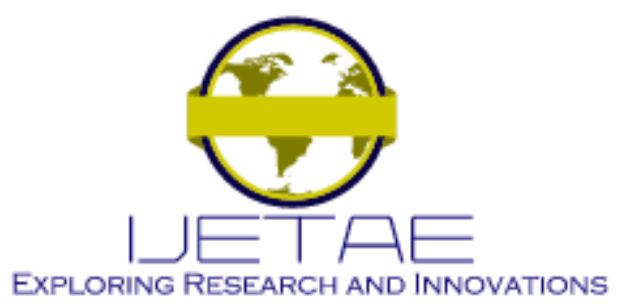

International Journal of Emerging Technology and Advanced Engineering

Website: www.ijetae.com (E-ISSN 2250-2459, Scopus Indexed, ISO 9001:2008 Certified Journal, Volume 11, Issue 09, September 2021)

In addition, the ease of software packages will ensure student familiarization in using the simulator with minimum supervision from the instructors. As a result, remote experimentation for students is achievable with the water tank simulator.

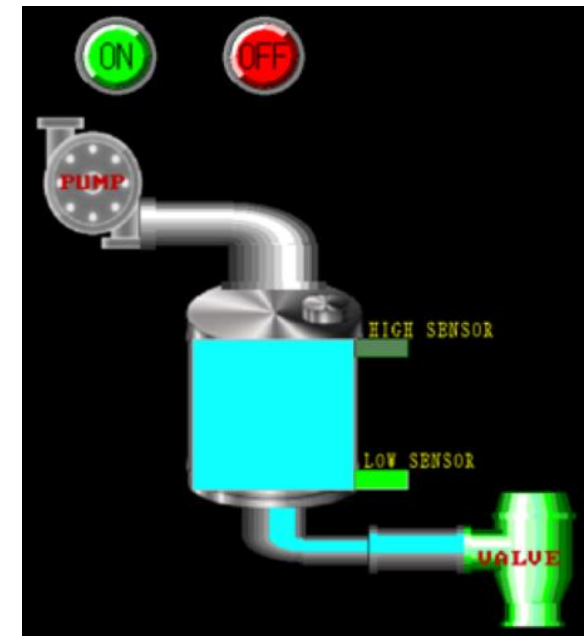

Figure 7. Water at maximum level condition

The water level simulator gives certain advantages in the teaching and learning process, especially in automationrelated subjects. The students can further understand PLC ladder programming through this simulator because it is directly connected with the HMI simulator without any physical setup from PLC to input-output devices. The advantage of no physical setup decreases the possibility of machine and component damages. Furthermore, every student can participate in the laboratory exercise repetitively without disconnecting and reconnecting the physical laboratory setup. On the contrary, physical setup cannot be fully exempted because it ensures student's psychomotor skills were tested in the laboratory. This is the main drawback of this simulator, where students will not acquire sufficient skill and knowledge on how to perform the wire connection between PLC to IO components. Hence this water level simulator is not developed for the psychomotor skill's evaluation.

\section{CONCLUSION}

This paper has demonstrated the development of a water tank simulator for experimentation purposes to substitute the actual water level control system hardware as its primary objective.
The hardware in reality, is very costly to buy for HLI that is having a budget constraint. Nevertheless, ensuring student's learning experiences were not hindered by these difficulties, an alternative approach was taken where the water level simulator was developed and introduced in the student's experiment session. The water level simulator has been designed with the fundamental concept of automation with ladder diagram programming for the input and output of the water tank to ensure that the water level simulator operates successfully. The simulator requires students to understand the theory and concept delivered in the lecture session before utilizing the simulator tool for the experimentation session. It is critical where students will not be able to operate the simulator if the fundamental concept of automation is not within the student's knowledge. This alternative approach is deemed the most suitable solution for budget constraints instead of purchasing expensive laboratory equipment.

\section{Acknowledgement}

The authors gratefully acknowledge the financial support from the Universiti Teknologi MARA Cawangan Johor through the Bestari Research Grant scheme phase 1/2020 (Project no: 600-UiTMCJ (PJIA. 5/2) ) to carry out this research project.

\section{REFERENCES}

[1] V. Alcácer and V. Cruz-Machado, "Scanning the Industry 4.0: A Literature Review on Technologies for Manufacturing Systems," Engineering Science and Technology, an International Journal, vol. 22, 2019, 899-919.

[2] M.o.E. Malaysia, "Malaysia Education Blueprint 2015 - 2025 (Higher Education)," ed. Malaysia, 2015.

[3] I. Burhan, S. Talib, and A. A. Azman, "Design and fabrication of Programmable Logic Controller Kit with multiple output module for teaching and learning purposes", 2012 IEEE 8th International Colloquium on Signal Processing and its Applications, 2012, 14-18.

[4] I. Burhan, A. A. Azman, and S. Talib, "Multiple input/outputs Programmable Logic Controller (PLC) module for educational applications", 2015 Innovation \& Commercialization of Medical Electronic Technology Conference (ICMET), 2015, 39-43.

[5] NM. Thamrin and M.M. Ismail, "Development of virtual machine for Programmable Logic Controller (PLC) by using STEPSTM programming method", 2011 IEEE International Conference on System Engineering and Technology, 2011, 138-142.

[6] F.H. Villa-López, J. García-Guzmán, J.V. Enríquez, S. Leal-Ortíz, and A. Ramírez, "Electropneumatic System for Industrial Automation: A Remote Experiment within a Web-Based Learning Environment," Procedia Technology, vol. 7, 2013, 198-207.

[7] S.J. Hsieh, "Web-based programmable logic controller learning system," in 32nd Annual Frontiers in Education, 2002, S2D-S2D. 


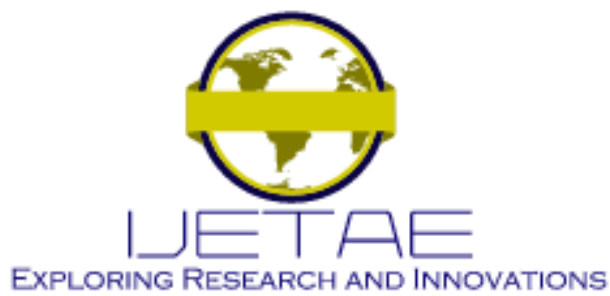

International Journal of Emerging Technology and Advanced Engineering Website: www.ijetae.com (E-ISSN 2250-2459, Scopus Indexed, ISO 9001:2008 Certified Journal, Volume 11, Issue 09, September 2021)

[8] H. Sheng-Jen, P.Y. Hsieh, and Z. Dongmin, "Web-based simulations and intelligent tutoring system for programmable logic controller", 33rd Annual Frontiers in Education, 2003. FIE 2003., 2003, T3ET3E.

[9] AJS del Pozo, J.M. Escaño, DM de la Peña, and F. Gómez-Estern, "3D simulator of industrial systems for control education with automated assessment," IFAC Proceedings Volumes, vol. 46,2013, 321-326.

[10] C.G. Sărăcin, I.D. Deaconu, and A.I. Chirilă, "Educational Platform Dedicated to the Study of Programmable Logic Controllers and the Human-Machine Interface", 2019 11th International Symposium on Advanced Topics in Electrical Engineering (ATEE), 2019, 1-4.

[11] V. Năvrăpescu, A. Chirilă, A. Deaconu, and I. Deaconu, "Educational platform for working with programmable logic controllers", 2015 9th International Symposium on Advanced Topics in Electrical Engineering (ATEE), 2015, 215-220.

[12] DD. Lucache, G. Gabor, and C.C. Dosoftei, "Integrated Learning in Electrical and Control Engineering Using an Educational Elevator System", 2020 International Conference and Exposition on Electrical And Power Engineering (EPE), 2020, 744-748.

[13] KBJ Anuradha, WMTG Wijewardhana, APAC Pathirana, A. MWKN Bandaranayake, SMBP Samarakoon, and AGBP Jayasekara, "Interactive Learning Platform for Programmable Logic Controllers with a Web Application," in 2019 Moratuwa Engineering Research Conference (MERCon), 2019, 370-375.

[14] BI. Oladapo, V.A. Balogun, A.O.M. Adeoye, C.O. Ijagbemi, A.S. Oluwole, I.A. Daniyan, et al., "Model design and simulation of automatic sorting machine using proximity sensor," Engineering Science and Technology, an International Journal, vol. 19, 2016, $1452-1456$.

[15] J. Alvarez, G. Díaz, and M. Macías, "Programming logical controllers using remote labs and virtual reality," in 2019 IEEE International Conference on Engineering Veracruz (ICEV), 2019, $1-4$.
[16] A.B. Gavali, S.A. Patil, and AR Koli, "Technology-Based Learning system in Programmable Logic Controller Education," in 2016 IEEE Eighth International Conference on Technology for Education (T4E), 2016, 264-265

[17] L.B. Palma, V. Brito, J. Rosas, and P. Gil, "WEB PLC simulator for ST programming," in 2017 4th Experiment@International Conference (exp.at'17), 2017, 303-308.

[18] A.R.M. Khairudin, A. Abu-Samah, N.A S. Aziz, M.A.F.M. Azlan, M.H.A. Karim, and N.M. Zian, "Design of Portable Industrial Automation Education Training Kit Compatible for IR 4.0," in 2019 IEEE 7th Conference on Systems, Process and Control (ICSPC), $2019,38-42$

[19] A.F.A. Awalludin, "Monitoring and controlling double carriage elevator system using CX-designer and CX-programmer", 2015 IEEE 6th Control and System Graduate Research Colloquium (ICSGRC), 2015, 151-157.

[20] Siemens. (2021, Sept, 12). "PLC Programming Software for Use With Simatic S7-1200 Basic Panels [Online]". Available: https://my.rs-online.com/web/p/plc-accessories/1417357/

[21] OMRON. (2021, Sept, 12). "PLC Programming Software for Use With CP1E Series and CP1L Series [Online] ". Availble: https://my.rs-online.com/web/p/plc-accessories/7055855

[22] Mitsubishi. (2021, Sept, 12). " PLC Programming Software for Use With MELSEC IQ-F Series Programmable Controllers, MELSEC IQ-R Series [Online]". Available: https://my.rsonline.com/web/p/plc-accessories/8772441

[23] Schneider Electric. (2021, Sept, 12). "PLC Programming Software for Use with OEM Machine [Online]". Avalaible: https://my.rsonline.com/web/p/plc-accessories/7702324 